\title{
Comparison on the Nutrient Plunder Capacity of Orychophragmus violaceus and Brassica napus L. Based on Electrophysiological Information
}

\author{
Cheng Zhang ${ }^{1,2}$, Yue $\mathrm{Su}^{3, *}$, Yanyou $\mathrm{Wu}^{2, *} \mathbb{D}$, Haitao $\mathrm{Li}^{3}$, Ying Zhou ${ }^{2}$ and Deke Xing ${ }^{1}$ \\ 1 Key Laboratory of Modern Agricultural Equipment and Technology, Ministry of Education, College of \\ Agricultural Engineering, Jiangsu University, Zhenjiang 212013, China; 2111816013@stmail.ujs.edu.cn (C.Z.); \\ xingdeke@ujs.edu.cn (D.X.) \\ 2 State Key Laboratory of Environmental Geochemistry, Institute of Geochemistry, Chinese Academy of \\ Sciences, Guiyang 550081, China; zhouying@mail.gyig.ac.cn \\ 3 Department of Agricultural Engineering, Guizhou Vocational College of Agriculture, Qingzhen 551400, \\ China; lisea02@126.com \\ * Correspondence: suyue09136@163.com (Y.S.); wuyanyou@mail.gyig.ac.cn (Y.W.)
}

Citation: Zhang, C.; Su, Y.; Wu, Y.; Li, H.; Zhou, Y.; Xing, D. Comparison on the Nutrient Plunder Capacity of Orychophragmus violaceus and Brassica napus L. Based on Electrophysiological Information. Horticulturae 2021, 7, 206 https://doi.org/10.3390/

horticulturae7080206

Academic Editor: Moreno Toselli

Received: 23 June 2021

Accepted: 19 July 2021

Published: 21 July 2021

Publisher's Note: MDPI stays neutral with regard to jurisdictional claims in published maps and institutional affiliations.

Copyright: (c) 2021 by the authors. Licensee MDPI, Basel, Switzerland. This article is an open access article distributed under the terms and conditions of the Creative Commons Attribution (CC BY) license (https:// creativecommons.org/licenses/by/ $4.0 /)$.
Abstract: The nutrient metabolism, growth and development of plants are strongly affected by its nutrient plunder, and plants have different adaptive mechanisms to low-nutrient environments. The electrophysiological activities involve almost all life processes of plants. In this study, the active transport flow of nutrient (NAF) and nutrient plunder capacity (NPC) of plants were defined based on leaf intrinsic impedance (IZ), capacitive reactance (IXc), inductive reactance (IXL) and capacitance (IC) to evaluate the nutrient plunder capacity of plants for the first time. The results indicate that Orychophragmus violaceus had higher $(p<0.01)$ NPC and IC and lower $(p<0.01)$ IR, IXc, IXL and IZ as compared to Brassica napus L., which supports a superior ion affinity and that it could be better adapted to low-nutrient environments. UAF and NPC of plants exhibited good correlations with crude protein, crude ash and water content, and precisely revealed the plunder capacity and adaptive strategies of plants to nutrients. The present work highlights that O. violaceus had superior NPC and ion affinity compared with B. napus, and provided a novel, rapid, reliable method based on the plant's electrophysiological information for real-time determination of the nutrient plunder capacity of plants.

Keywords: electrophysiological information; nutrient plunder; membrane protein; Orychophragmus violaceus; Brassica napus L.

\section{Introduction}

A plant's nutrient plunder strongly influences various physiological processes of plants, such as nutrients utilization, energy metabolism, stress resistance, growth and development, etc. [1-3]. Plants have different adaptive mechanisms to low-nutrient environments caused by soil erosion, karstification and unsuitable cultivation, etc. [4-7]. Moreover, biotic or abiotic stresses including drought, cold, etc., may also lead to low nutrition in plants [4-6]. In the karst regions of Southwest China, karst soils with characteristics of low nutrition, drought, high $\mathrm{pH}$, high bicarbonate and high calcium and magnesium frequently result in crop yield reduction, ecological fragility and economic losses $[4,5]$. The adaptive mechanism, detection technology and screening configuration of the karst-adaptable plants have always been the eternal topic of researchers. For instance, $\mathrm{Wu}$ et al. [6] found on the basis of ion absorption kinetics that Orychophragmus violaceus was more able to absorb or plunder $\mathrm{K}^{+}, \mathrm{NH}_{4}{ }^{+}$and $\mathrm{H}_{2} \mathrm{PO}_{4}{ }^{-}$from the environment as compared to Brassica napus L., and more adapted to karst environments. Xing and Wu [7] demonstrated that the adaptability of plants to low nutrients was not only reflected in the strong affinity of plants to nutrients, but also in the mechanism of nutrient determining 
growth. Therefore, the development of detection methods for plant nutrient plunder is of great significance for the revelation of adaptive mechanisms, ecological restoration and economic development.

A plant's electrophysiological activities, such as charge separation, electron movement, proton and dielectric transport, etc. involve almost all its life processes [8-11]. Membrane lipids and proteins, the main components of the plant cell membrane, have a high electrical resistivity, enabling cells to store electric charges [8,9]. Thus, the electrical properties of plant cells are most closely related to the cell membrane with an electric double layer. Generally, a mesophyll cell can be considered equivalent to a concentric sphere capacitor with both inductor and resistor function, and the ions, ion groups and electric dipoles in mesophyll cells are electrolytes of the cell capacitor [9-12]. The electrophysiological activities of plants change with the ion, ion group and electric dipole concentrations of plant cells. The abiotic or biotic stress, such as drought, heat, cold, salt, diseases and insect pests, exogenous force, etc., can directly or indirectly evoke structure, composition and ion permeability changes of plant cells, causing dramatic changes in the electrical parameters of plants [13-19]. Therefore, a plant's electrical parameters are the fastest physiological response to environmental stimulations [20-23].

Previously, plant electrical parameters were measured by a traditional technique based on two electrodes inserted into a plant stem or leaf $[24,25]$. Recently, as a major discovery in plant electrophysiology, the theoretically intrinsic relationships among the clamping force $(\mathrm{F})$ and leaf resistance $(\mathrm{R})$, impedance $(\mathrm{Z})$, capacitive reactance $\left(\mathrm{X}_{\mathrm{c}}\right)$ or inductive reactance $(\mathrm{XL})$ were revealed as $\mathrm{R}, \mathrm{Z}, \mathrm{Xc}$ or $\mathrm{XL}=\mathrm{y}+\mathrm{k} e^{-\mathrm{bF}}$ based on bioenergetics for the first time in our previous studies $[22,23]$. When the clamping force is $0(\mathrm{~F}=0)$, then the intrinsic $\mathrm{R}(\mathrm{IR})$, intrinsic $Z$ (IZ), intrinsic $X_{c}\left(I_{C}\right)$ and intrinsic $X_{L}$ (IXL) of plant leaves could be monitored as IR, IZ, IXc or IXL $=y+k$. This method greatly overcomes and avoids various drawbacks of the traditional impalement method, such as lack of representativeness, poor stability and low reproducibility, etc. At the same time, it is a rapid, undamaged, simple, accurate and real-time approach for monitoring a plant's electrophysiological parameters.

$\mathrm{Z}$ and capacitance $(\mathrm{C})$ are the most common electrical parameters to evaluate the varying physiological status of plants [26-30]. For instance, Zhang et al. [20] reported that plants' electrophysiological properties could reflect their response to drought stress and firstly defined leaf tensity based on leaf $C$ to represent plant drought resistance. Moreover, leaf tensity could evaluate the irrigation effects of the diluted, salted water, determine the water requirement information of plants and predict the re-watering time of plants [20,21,28,29]. Xing et al. [21] found that leaf $Z$ provides more reliable water information of plants than water potential, and defined leaf water dissipation rate based on leaf $Z$. In our previous study, the intracellular water-holding capacity, water use efficiency, water-holding time and water transfer rate of plants on the basis of leaf $Z, C$ and $X_{c}$ were defined, which accurately revealed the life strategies and diversity of intracellular water metabolism in plants [22].

Generally, the ratio of total nutrient in plants to total input nutrient is the most common evaluation index of plant nutrient utilization, but it cannot directly reflect the nutrient plunder or transport information [31,32]. Moreover, the minimum concentration of plant ion absorption based on ion absorption kinetics can directly reflect a plant's nutrient plunder capacity; however, it cannot be used for in situ online detection, and the operation is complex, time consuming and demanding [6]. The stronger a plant's nutrient plunder capacity, the stronger its affinity to ions, and the higher the concentration difference between the inside and outside of plant cells. Cell membrane proteins are responsible for the nutrient transport inside and outside the plant cells [33,34]. Thus, the composition characteristics of surface proteins and binding proteins on the cell membrane determine the nutrient transport capacity of cells. In our previous study, the results demonstrate that $X_{c}$ and $X L$ could, respectively, be used to manifest the relative composition characteristic of surface and binding proteins in cell membrane, and the nutrient flux per unit area nutrient transfer rate and nutrient transport capacity in plants based on leaf $R, Z, X c, X L$ 
and $C$ were defined for the first time, which accurately revealed the nutrient transport strategies of plants [23]. Although this method can reflect the nutrient transport capacity of plants, it cannot directly reflect the plunder capacity (or active transport capacity) of plant nutrients. Thus far, the rapid determination of the plunder capacity (or active transport capacity) of plant nutrients has also not been reported.

The binding protein is most closely related to the active transport of nutrients; thus, the ratio of $X_{c}$ and $X L$ can represent the relative plunder information (or active transport information) of plant nutrients. In this study, the nutrient plunder capacities of two plants (B. napus and O. violaceus) with different adaptability to karst environments were studied. Firstly, the equations between clamping forces and leaf $R, X_{c}$ and $X L$ of plants were fitted. Subsequently, the leaf IR, IZ, IXc, IXL and IC were calculated using these fitting equation parameters. Then, the active transport flow of nutrient (NAF) and the nutrient plunder capacity (NPC) of plants were defined based on leaf IZ, IXc, IXL and IC to evaluate the nutrient plunder capacity of plants for the first time. This study aims to reveal the different nutrient plunder strategies of $B$. napus and O. violaceus, and provide a novel, rapid, reliable technique for real-time determination of the nutrient plunder capacity of plants.

\section{Materials and Methods}

\subsection{Experimental Materials}

B. napus and O. violaceus were grown in the potted agriculture soil of Guizhou University in Huaxi County, Guizhou Province $\left(26^{\circ} 42^{\prime} \mathrm{N}, 106^{\circ} 67^{\prime}\right.$ E). The average annual temperature, sunshine hour and precipitation in Huaxi County are $15.7^{\circ} \mathrm{C}, 1164.9 \mathrm{~h}$ and $1215.7 \mathrm{~mm}$, respectively. The soil had total organic matter of $29.58 \mathrm{~g} \mathrm{~kg}^{-1}$, soil moisture content of $16.33 \%$ and a $\mathrm{pH}$ value of 6.35 . The fresh fully expanded leaves of plants were used as tested materials. The tested leaves were sampled and measured at $\sim 8-10$ a.m. on sunny days, and the measured temperature was $25.0 \pm 2.0^{\circ} \mathrm{C}$.

\subsection{Measurement of Electrophysiological Parameters of Plant Leaves under Different Clamping Forces}

The fresh, fully expanded leaves were sampled from the third, fourth and fifth leaf positions of each branch and soaked in water for $30 \mathrm{~min}$ after being weighed. Then, the water on the leaf surface was removed and measured, and three branches of each plant were measured. Afterwards, the electrophysiological parameters of the same leaves were measured, and their biochemical parameters were measured. The electrophysiological parameters of plant leaves were measured by an LCR-6300 tester (Gwinstek, Taiwan, China) the test parameters of which referred to our previous studies [21-23]. The parallel connection mode of LCR was selected, and the tested voltage and frequency were $1.5 \mathrm{~V}$ and $3 \mathrm{kHz}$, respectively. Leaf was firstly put between the two electrodes of a self-made parallelplate capacitor, the schematic diagram of which is shown in our previous study [22]. Then, leaf $C, R$ and $Z$ under different clamping forces were continuously collected and saved 11 13 data for each clamping force. Different clamping force was achieved by adding the same quality iron blocks. Finally, leaf Xc and XL were calculated, respectively, according to Formulas (1) and (2):

$$
\begin{gathered}
\mathrm{XC}_{\mathrm{C}}=\frac{1}{2 \pi \mathrm{fC}} \\
\frac{1}{-\mathrm{XL}}=\frac{1}{\mathrm{Z}}-\frac{1}{\mathrm{R}}-\frac{1}{\mathrm{Xc}_{\mathrm{C}}}
\end{gathered}
$$

where $X_{c}$ : capacitive reactance, $\pi$ : 3.1416 , f: frequency, C: capacitance, $\mathrm{XL}$ : inductive reactance, $Z$ : impedance, $R$ : resistance.

\subsection{Calculation of Intrinsically Electrophysiological Parameters of Plant Leaves}

The intrinsic $C, R, Z, X_{c}$ and $X L$ of plant leaves were calculated as described by our previous studies $[22,23]$. The theoretically intrinsic relationships between the clamping force and leaf $\mathrm{R}, \mathrm{Z}, \mathrm{Xc}_{\mathrm{c}}$ or $\mathrm{XL}$ were revealed as $\mathrm{R}, \mathrm{Z}, \mathrm{X}_{\mathrm{c}}$ or $\mathrm{XL}=\mathrm{y}+\mathrm{k} e^{-\mathrm{bF}}$ based on the Nernst equation for the first time in our previous studies [22,23]. When the clamping force 
is $0(F=0)$, then the intrinsic $R, Z, X_{c}$ and $X L$ of plant leaves could be monitored as IR, IZ, IXc or IXL $=y+k$. Therefore, the intrinsically electrophysiological parameters of plant leaves can be calculated by fitting the equation of clamping force and electrophysiological parameters of plant leaves. The simple derivation of $\mathrm{Z}, \mathrm{R}, \mathrm{Xc}$ or $\mathrm{XL}=\mathrm{y}+\mathrm{k} e^{-\mathrm{bF}}$ is as follows.

A mesophyll cell can be regarded as a concentric sphere capacitor with both inductor and resistor functions, and its ions, ion groups and electric dipoles are used as electrolytes of the capacitor. The leaf $C, R, Z, X c$ and $X L$ varied with the ion, ion group and electric dipole concentrations in the plant leaves, and different clamping forces inevitably led to changes in the ion, ion group and electric dipole concentrations in plant leaves. According to the bioenergetics, the Nernst equation can be used to quantitatively describe the potential of electrolytes inside and outside the cell membrane [22,23]. Thus, the concentration differences in the electrolytes that respond to $\mathrm{R}$ inside and outside the cell membrane obey the Nernst equation and can be expressed as follows [16]:

$$
\mathrm{E}-\mathrm{E}^{0}=\frac{\mathrm{R}_{0} \mathrm{~T}}{\mathrm{n}_{\mathrm{R}} \mathrm{F}_{0}} \ln \frac{\mathrm{C}_{\mathrm{i}}}{\mathrm{C}_{\mathrm{o}}}
$$

where E: electromotive force $(\mathrm{V}), \mathrm{E}^{0}$ : standard electromotive force $(\mathrm{V}), \mathrm{R}_{0}$ : gas constant (8.314570 $\left.\mathrm{J} \mathrm{K}^{-1} \mathrm{~mol}^{-1}\right)$, $\mathrm{T}$ : thermodynamic temperature $(\mathrm{K}), \mathrm{C}_{\mathrm{i}}$ : the concentration of the electrolytes that respond to $\mathrm{R}$ inside the cell membrane $\left(\mathrm{mol} \mathrm{L}^{-1}\right), \mathrm{C}_{\mathrm{o}}$ : the concentration of the electrolytes that respond to $\mathrm{R}$ outside the cell membrane $\left(\mathrm{mol} \mathrm{L}^{-1}\right), \mathrm{F}_{0}$ : Faraday constant $\left(96,485 \mathrm{C} \mathrm{mol}^{-1}\right)$ and $\mathrm{n}_{\mathrm{R}}$ : the number of transferred electrolytes (mol).

When a leaf cell container is subjected to clamping force, the pressure work by the clamping force on leaf cells can be converted into the internal energy of the electromotive force, that is:

$$
P V=a E=a E^{0}+\frac{a R_{0} T}{n_{R} F_{0}} \ln \frac{C_{i}}{C_{o}}
$$

where $\mathrm{P}$ : the pressure intensity on the leaf cells $(\mathrm{Pa})$, a: the energy conversion coefficient of the electromotive force and V: cell volume $\left(\mathrm{m}^{3}\right)$. Formula (5) can be obtained by multi-step derivation:

$$
\mathrm{R}=\frac{\mathrm{f}_{0}}{\mathrm{C}_{\mathrm{T}}}+\frac{\mathrm{f}_{0}}{\mathrm{C}_{\mathrm{T}}} \mathrm{e}^{\frac{\mathrm{n}_{\mathrm{R}} \mathrm{F}_{0} \mathrm{E}^{0}}{\mathrm{R}_{0} \mathrm{~T}}} \mathrm{e}^{\left(-\frac{\mathrm{d} \mathrm{n}_{\mathrm{R}} \mathrm{F}_{0}}{\mathrm{a} \mathrm{R}_{0} \mathrm{~T}} \mathrm{~F}\right)}
$$

where $d=\frac{V}{S}, C_{T}=C_{o}+C_{i}$, and $f_{0}$ : the ratio coefficient of the conversion between $C_{i}$ and $R$. For the same leaf, the $d, a, E^{0}, R_{0}, T, n_{R}, F_{0}, C_{T}$ and $f_{0}$ of Formula (12) are constant. Let $\mathrm{y}_{0}=\frac{\mathrm{f}_{0}}{\mathrm{C}_{\mathrm{T}}}, \mathrm{k}_{1}=\frac{\mathrm{f}_{0}}{\mathrm{C}_{\mathrm{T}}} \mathrm{e}^{\frac{\mathrm{n}_{\mathrm{R}} \mathrm{F}_{0} \mathrm{E}^{0}}{\mathrm{R}_{0} \mathrm{~T}}}, \mathrm{~b}_{1}=\frac{\mathrm{d} \mathrm{n}_{\mathrm{R}} \mathrm{F}_{0}}{\mathrm{a} \mathrm{R}_{0} \mathrm{~T}}$

$$
\mathrm{R}=+\mathrm{y}_{0} \mathrm{k}_{1} e^{-\mathrm{b}_{1} \mathrm{~F}}
$$

where $y_{0}, k_{1}$ and $b_{1}$ are fitting equation parameters. When $F=0$, the IR of the plant leaves could be monitored by IR $=\mathrm{y}_{0}+\mathrm{k}_{1}$.

Similar to $\mathrm{R}$, the intrinsic relationship of leaf $\mathrm{Xc}_{\mathrm{c}}$ and $\mathrm{F}$ is:

$$
\mathrm{X}_{\mathrm{c}}=\mathrm{p}_{0}+\mathrm{k}_{2} \mathrm{e}^{-\mathrm{b}_{2} \mathrm{~F}}
$$

where $\mathrm{p}_{0}, \mathrm{k}_{2}$ and $\mathrm{b}_{2}$ are fitting equation parameters. When $\mathrm{F}=0$, the IXc of plant leaves could be monitored by IXc $=\mathrm{p}_{0}+\mathrm{k}_{2}$.

Similar to $\mathrm{R}$, the intrinsic relationship of leaf $\mathrm{XL}$ and $\mathrm{F}$ is:

$$
\mathrm{XL}=\mathrm{q}_{0} \mathrm{k}_{3} \mathrm{e}^{-\mathrm{b}_{3} \mathrm{~F}}
$$

where $q_{0}, k_{3}$ and $b_{3}$ are fitting equation parameters. When $F=0$, the IXL of plant leaves could be monitored by IXL $=\mathrm{q}_{0}+\mathrm{k}_{3}$. 
Subsequently, the IZ and IC of plant leaves were calculated, respectively, according to Formulas (9) and (10):

$$
\begin{gathered}
\frac{1}{\mathrm{IZ}}=\frac{1}{\mathrm{IR}}+\frac{1}{\mathrm{IXC}}-\frac{1}{\mathrm{IXL}} \\
\mathrm{IC}=\frac{1}{2 \pi \mathrm{fI} \mathrm{XC}_{\mathrm{C}}}
\end{gathered}
$$

where $\pi=3.1416$ and $\mathrm{f}=$ frequency.

\subsection{Definition of the Nutrient Plunder Parameters}

The results of our previous study indicate that IXC and IXL could be used to manifest the relative composition characteristic of cell membrane proteins, and are inversely proportional to the amount of surface and binding proteins that induce membrane $X_{c}$ and $X L$ in plant leaves, respectively [23]. The nutrient flux per unit area (UNF), nutrient transfer rate (NTR) and nutrient transport capacity (NTC) were defined and applied for the first time.

$$
\begin{gathered}
\mathrm{UNF}=\frac{\mathrm{IR}}{\mathrm{IXc}}+\frac{\mathrm{IR}}{\mathrm{IXL}} \\
\mathrm{NTR}=\frac{\sqrt{(\mathrm{IC})^{3}}}{\mathrm{IC} \times \mathrm{IZ}} \\
\mathrm{NTC}=\mathrm{UNF} \times \mathrm{NTR}
\end{gathered}
$$

The stronger a plant's nutrient plunder capacity, the stronger its affinity to ions. It has been estimated that $15 \sim 30 \%$ of the nuclear gene-encoded proteins are involved in nutrient transport on the cell membrane $[16,27]$. The surface and binding proteins on the cell membrane strongly influence the transport and metabolism of nutrients. The binding protein is most closely related to the active transport (or plunder capacity) of nutrients. Thus, the active transport (or plunder capacity) flow of nutrients (NAF) could be represented by Formula (14):

$$
\mathrm{UAF}=\frac{\mathrm{IXc}}{\mathrm{IXL}}
$$

Therefore, the nutrient plunder capacity (NPC) is NAF multiplied by NTR:

$$
\mathrm{NPC}=\mathrm{UAF} \times \mathrm{NTR}
$$

\subsection{Determination of Water Content, Crude Ash and Crude Protein}

After the determination of the electrophysiological parameters, the biochemical parameters of the same leaves were measured. Water contents of plant leaves were determined by the drying method, and the fresh weight of plant leaves was measured before the determination of electrophysiological parameters. After the determination of water contents of plant leaf samples, they were smashed and mixed for analysis. Then, crude ash and crude protein of samples were determined as described by Zhang et al. [23].

\subsection{The Nutrient Plunder Parameters of Four Plants}

According to the electrophysiological parameters of the four plants in the previous study [23], their nutrient plunder capacities were calculated. Four plants were Broussonetia papyrifera in the agricultural soil, B. papyrifera in the moderately rocky desertification soil, Solanum tuberosum L. and Capsicum annuum L., respectively.

\subsection{Data Analyses}

Data are expressed as the means \pm standard deviation (SD) $(n=9)$. Analysis of variance and correlation for the experimental data were carried out SPSS 18.0 software (SPSS Inc., Chicago, IL, USA). One-way analysis of variance was performed by Duncan's test. A correlation matrix was based on Pearson's correlation coefficients. 


\section{Results}

\subsection{Fitting Equation Parameters of B. napus and O. violaceus}

As shown in Table 1, the correlation coefficients $(R)$ of the fitting equations of R-F, Xc-F, and XL-F in B. napus leaves ranged from 0.9769 to $0.9998,0.9988$ to 0.9997 and 0.9950 to 0.9997 , respectively; while in O. violaceous leaves, they ranged from 0.9851 to 0.9989 , 0.9981 to 0.9996 and $0.9950 \sim 0.9997$, respectively. Meanwhile, all $p$ values of the fitting equation parameters were lower than 0.0001. The results presented here show that the relationships among clamping force and $\mathrm{R}, \mathrm{Xc}$ and $\mathrm{XL}$ of $B$. napus and $O$. violaceus leaves had good correlations.

Table 1. The fitting equation parameters of $B$. napus and O. violaceus. R: resistance, $\mathrm{Xc}_{\mathrm{c}}$ capacitive reactance, $\mathrm{XL}$ : inductive reactance, F: clamping force.

\begin{tabular}{|c|c|c|c|c|c|c|c|c|c|c|}
\hline \multirow{2}{*}{ Plants } & \multirow{2}{*}{$\begin{array}{l}\text { Branch- } \\
\text { Leaves }\end{array}$} & \multicolumn{3}{|c|}{ R-F } & \multicolumn{3}{|c|}{ Xc-F } & \multicolumn{3}{|c|}{ XL-F } \\
\hline & & $\mathrm{y}_{0} / \mathbf{k}_{1} / \mathbf{b}_{1}$ & $R$ & $p<$ & $\mathrm{p}_{0} / \mathrm{k}_{2} / \mathrm{b}_{2}$ & $R$ & $p<$ & $\mathrm{q}_{0} / \mathrm{k}_{2} / \mathrm{b}_{2}$ & $R$ & $p<$ \\
\hline \multirow{9}{*}{$B n$} & $1-3$ & $0.1275 / 0.1372 / 0.5297$ & 0.9970 & 0.0001 & $0.1165 / 0.2498 / 0.4215$ & 0.9995 & 0.0001 & $0.1775 / 0.6429 / 0.8423$ & 0.9995 & 0.0001 \\
\hline & $1-4$ & $0.1066 / 0.2712 / 0.8598$ & 0.9984 & 0.0001 & $0.1012 / 0.4728 / 0.8270$ & 0.9997 & 0.0001 & $0.1637 / 0.1833 / 0.2880$ & 0.9987 & 0.0001 \\
\hline & $1-5$ & $0.0946 / 0.1954 / 0.8879$ & 0.9998 & 0.0001 & $0.0981 / 0.2483 / 0.6364$ & 0.9996 & 0.0001 & $0.2118 / 0.2358 / 0.7457$ & 0.9997 & 0.0001 \\
\hline & $2-3$ & $0.1289 / 0.2148 / 1.0182$ & 0.9850 & 0.0001 & $0.12360 .3048 / 0.8187$ & 0.9995 & 0.0001 & $0.2718 / 0.4526 / 1.3261$ & 0.9950 & 0.0001 \\
\hline & $2-4$ & $0.1289 / 0.2149 / 1.0183$ & 0.9850 & 0.0001 & $0.1154 / 0.1574 / 0.4170$ & 0.9995 & 0.0001 & $0.2916 / 0.2151 / 0.5994$ & 0.9967 & 0.0001 \\
\hline & $2-5$ & $0.1401 / 0.1851 / 0.9759$ & 0.9945 & 0.0001 & $0.1072 / 0.2887 / 0.6193$ & 0.9991 & 0.0001 & $0.2133 / 0.3943 / 0.7264$ & 0.9984 & 0.0001 \\
\hline & $3-3$ & $0.1398 / 0.1674 / 1.3117$ & 0.9769 & 0.0001 & $0.1251 / 0.2629 / 0.6037$ & 0.9997 & 0.0001 & $0.2652 / 0.3072 / 0.7873$ & 0.9981 & 0.0001 \\
\hline & $3-4$ & $0.1636 / 0.1952 / 0.9500$ & 0.9967 & 0.0001 & $0.1123 / 0.2999 / 0.6879$ & 0.9995 & 0.0001 & $0.2469 / 0.4716 / 0.8073$ & 0.9991 & 0.0001 \\
\hline & $3-5$ & $0.1607 / 0.1982 / 0.9000$ & 0.9960 & 0.0001 & $0.1085 / 0.2127 / 0.5295$ & 0.9988 & 0.0001 & $0.2041 / 0.2672 / 0.5842$ & 0.9984 & 0.0001 \\
\hline \multirow{9}{*}{$O v$} & $1-3$ & $0.0304 / 0.0758 / 0.5905$ & 0.9851 & 0.0001 & $0.0575 / 0.0788 / 0.4176$ & 0.9987 & 0.0001 & $0.1146 / 0.0926 / 0.4672$ & 0.9980 & 0.0001 \\
\hline & $1-4$ & $0.0334 / 0.0870 / 0.2712$ & 0.9976 & 0.0001 & $0.0342 / 0.1014 / 0.4579$ & 0.9993 & 0.0001 & $0.0615 / 0.1558 / 0.3704$ & 0.9990 & 0.0001 \\
\hline & $1-5$ & $0.0607 / 0.0941 / 0.6812$ & 0.9871 & 0.0001 & $0.0459 / 0.1070 / 0.5978$ & 0.9985 & 0.0001 & $0.0913 / 0.1707 / 0.6345$ & 0.9950 & 0.0001 \\
\hline & $2-3$ & $0.0472 / 0.0531 / 0.1987$ & 0.9973 & 0.0001 & $0.0413 / 0.0816 / 0.3194$ & 0.9981 & 0.0001 & $0.0788 / 0.1117 / 0.2786$ & 0.9991 & 0.0001 \\
\hline & $2-4$ & $0.0120 / 0.0320 / 0.1354$ & 0.9953 & 0.0001 & $0.0303 / 0.0504 / 0.3437$ & 0.9994 & 0.0001 & $0.0591 / 0.0619 / 0.2906$ & 0.9996 & 0.0001 \\
\hline & $2-5$ & $0.0444 / 0.0545 / 0.6730$ & 0.9989 & 0.0001 & $0.0368 / 0.0777 / 0.7161$ & 0.9993 & 0.0001 & $0.0695 / 0.1127 / 0.6999$ & 0.9994 & 0.0001 \\
\hline & $3-3$ & $0.0370 / 0.0648 / 0.3248$ & 0.9946 & 0.0001 & $0.0496 / 0.0796 / 0.3647$ & 0.9994 & 0.0001 & $0.0984 / 0.0994 / 0.3576$ & 0.9997 & 0.0001 \\
\hline & $3-4$ & $0.0348 / 0.0558 / 0.2441$ & 0.9973 & 0.0001 & $0.0325 / 0.0753 / 0.4173$ & 0.9996 & 0.0001 & $0.0606 / 0.1083 / 0.3472$ & 0.9993 & 0.0001 \\
\hline & $3-5$ & $0.0526 / 0.0743 / 0.6778$ & 0.9934 & 0.0001 & $0.0414 / 0.0920 / 0.6442$ & 0.9988 & 0.0001 & $0.0805 / 0.1416 / 0.6606$ & 0.9973 & 0.0001 \\
\hline
\end{tabular}

Note: Bn: B. napus, Ov: O. violaceus.

\subsection{Electrophysiological Information and Nutrient Plunder Capacity of B. napus and O. violaceus}

The intrinsic electrophysiological information and nutrient plunder capacity of $B$. napus and O. violaceus are listed in Tables 2 and 3. As shown in Table 2, the leaf IR, IXc, IXL and IZ of $B$. napus are significantly $(p<0.01)$ higher than those of $O$. violaceus, and its IC is significantly lower $(p<0.01)$ than that of $O$. violaceus. Moreover, the leaf UNF and UAF of B. napus are significantly $(p<0.05)$ higher than those of $O$. violaceus, but its NTR, NTC and NPC are significantly lower $(p<0.01)$ than those of O. violaceus (Table 3 ). As displayed in Figure 1, O. violaceus has higher $(p<0.01)$ water content, crude protein and crude ash compared with $B$. napus. These results demonstrate that the high water and ash content of $O$. violaceus supported its vigorous growth (high IC, low IR, IXc, IXL and IZ) and high NTR, which promoted the transport, plunder and utilization of nutrients. Furthermore, the high protein of O. violaceus also accelerated its NTC and NPC.

Table 2. The electrophysiological parameters of B. napus and O. violaceus. IR: intrinsic resistance, IXc: intrinsic capacitive reactance, IXL: intrinsic inductive reactance, IZ: intrinsic impedance, IC: intrinsic capacitance.

\begin{tabular}{cccccc}
\hline Plants & IR $(\mathbf{M} \Omega)$ & IXc $\mathbf{( M \Omega )}$ & IXL $\mathbf{( M \Omega )}$ & IZ $\mathbf{( M \Omega )}$ & IC $(\mathbf{p F})$ \\
\hline$B n$ & $0.33 \pm 0.04^{\mathrm{aA}}$ & $0.29 \pm 0.04^{\mathrm{aA}}$ & $0.39 \pm 0.08^{\mathrm{aA}}$ & $0.58 \pm 0.15^{\mathrm{aA}}$ & $141.48^{\mathrm{A}} \pm 28.45^{\mathrm{bB}}$ \\
Ov & $0.10 \pm 0.03^{\mathrm{bB}}$ & $0.08 \pm 0.01^{\mathrm{bB}}$ & $0.12 \pm 0.02^{\mathrm{bB}}$ & $0.20 \pm 0.04^{\mathrm{bB}}$ & $442.25 \pm 91.38^{\mathrm{aA}}$ \\
\hline
\end{tabular}

Note: Values indicate the mean $\pm \mathrm{SD}, n=9$. Small letters indicate significant differences at $5 \%$ level $(p<0.05)$, and capital letters indicate significant differences at $1 \%$ level $(p<0.01)$. Bn: B. napus, Ov: O. violaceus. 
Table 3. The nutrient plunder capacity of B. napus and O. violaceus. UNF: the nutrient flux per unit area, NTR: nutrient transfer rate, NTC: nutrient transport capacity, NAF: the active transport flow of nutrient, NPC: the nutrient plunder capacity.

\begin{tabular}{cccccc}
\hline Plants & UNF & NTR & NTC & UAF & NPC \\
\hline$B n$ & $1.49 \pm 0.30^{\mathrm{aA}}$ & $46.83 \pm 14.48^{\mathrm{bB}}$ & $69.19 \pm 27.13^{\mathrm{bB}}$ & $0.73 \pm 0.36^{\mathrm{aA}}$ & $30.20 \pm 5.10^{\mathrm{bB}}$ \\
$\mathrm{Ov}$ & $1.36 \pm 0.20^{\mathrm{bA}}$ & $295.36 \pm 15.63^{\mathrm{aA}}$ & $375.88 \pm 10.59^{\mathrm{aA}}$ & $0.63 \pm 0.03^{\mathrm{bA}}$ & $189.24 \pm 68.52^{\mathrm{aA}}$ \\
\hline
\end{tabular}

Note: Values indicate the mean $\pm \mathrm{SD}, n=9$. Small letters indicate significant differences at $5 \%$ level $(p<0.05)$, and capital letters indicate significant differences at $1 \%$ level $(p<0.01)$. Bn: B. napus, Ov: O. violaceus.

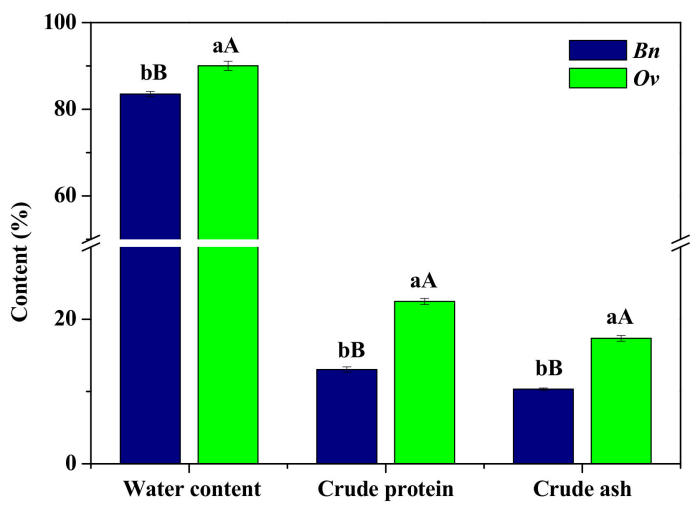

Figure 1. The content of water, crude protein and crude ash of leaves in B. napus and O. violaceus. Note: Values indicate the mean $\pm \mathrm{SD}, n=9$. Small letters indicate significant differences at $5 \%$ level $(p<0.05)$, and capital letters indicate significant differences at $1 \%$ level $(p<0.01)$. Bn: B. napus, Ov: O. violaceus.

\subsection{Correlation of Electrophysiological Information and Nutrient Plunder Parameters}

As shown in Table 4, IR, IXc, IXL and IZ are negatively correlated with NTR, UAF, NPC, water content, crude protein and crude ash, while IC is positively correlated with those. NTR, UAF and NPC are positively correlated with water content, crude protein and crude ash. IR of B. napus is significantly correlated with its NTR, and its IXc and IZ are significantly correlated with its NTR; IXc of $O$. violaceus is significantly correlated with its NTR, and its IC is significantly correlated with its NTR. IR and IXL of O. violaceus are significantly correlated with its NAF, and its IXc and IZ are significantly correlated with its NAF. IXC, IXL and IC of B. napus are significantly correlated with its NPC, and IC of $O$. violaceus is significantly correlated with its NPC. IR of B. napus is significantly correlated with its crude protein; IXc, IXL and IZ of $O$. violaceus are significantly correlated with its crude protein. IXL of B. napus is significantly correlated with its crude ash. IXc of B. napus is significantly correlated with its water content, and its IZ and IC are significantly correlated with its water content; IR, IXc, IXL and IZ of O. violaceus are significantly correlated with its water content, and its IC is significantly correlated with its water content. NTR of B. napus is significantly correlated with its crude protein, and NTR of O. violaceus is significantly correlated with its crude protein and water content. NAF of $O$. violaceus is significantly correlated with its water content. NPC of B. napus is significantly correlated with its crude protein, crude ash and water content, and NPC of O. violaceus is significantly correlated with its crude ash and water content. These results exhibit that the electrophysiological information and nutrient plunder capacity of plants demonstrate good correlations with nutrients and water. 
Table 4. Correlation between the electrophysiological information and nutrient plunder parameters of $B$. napus and O. violaceus. IR: intrinsic resistance, IXc: intrinsic capacitive reactance, IXL: intrinsic inductive reactance, IZ: intrinsic impedance, IC: intrinsic capacitance, NTR: nutrient transfer rate, NAF: the active transport flow of nutrient, NPC: the nutrient plunder capacity.

\begin{tabular}{|c|c|c|c|c|c|c|c|c|c|c|c|c|}
\hline \multirow{2}{*}{ Parameters } & \multicolumn{6}{|c|}{$B n$} & \multicolumn{6}{|c|}{$O v$} \\
\hline & NTR & NAF & NPC & $\begin{array}{l}\text { Crude } \\
\text { Protein }\end{array}$ & $\begin{array}{l}\text { Crude } \\
\text { Ash }\end{array}$ & $\begin{array}{c}\text { Water } \\
\text { Content }\end{array}$ & NTR & NAF & NPC & $\begin{array}{l}\text { Crude } \\
\text { Protein }\end{array}$ & $\begin{array}{l}\text { Crude } \\
\text { Ash }\end{array}$ & $\begin{array}{c}\text { Water } \\
\text { Content }\end{array}$ \\
\hline IR & $-0.661 *$ & -0.410 & -0.436 & $-0.835^{* *}$ & -0.329 & -0.087 & -0.502 & -0.835 ** & -0.426 & -0.410 & -0.178 & -0.929 ** \\
\hline IXc & -0.905 ** & -0.071 & $-0.726^{*}$ & -0.024 & -0.039 & $-0.907^{* *}$ & $-0.609^{*}$ & $-0.606^{*}$ & -0.631 * & -0.624 * & -0.538 & -0.938 ** \\
\hline IXL & -0.483 & -0.084 & $-0.662 *$ & -0.378 & $-0.851^{* *}$ & -0.079 & -0.549 & -0.780 * & -0.470 & $-0.558^{*}$ & -0.326 & -0.954 ** \\
\hline IZ & $-0.907^{* *}$ & -0.030 & -0.478 & -0.296 & -0.350 & -0.564 * & -0.479 & $-0.805^{* *}$ & -0.456 & $-0.553 *$ & -0.263 & $-0.918^{* *}$ \\
\hline IC & 0.488 & 0.284 & 0.760 * & 0.194 & 0.184 & $0.759 *$ & $0.969^{* *}$ & 0.072 & 0.471 & 0.326 & 0.520 & 0.611 * \\
\hline NTR & & & & $0.753 *$ & 0.316 & 0.470 & & & & $0.718^{*}$ & 0.343 & $0.645^{*}$ \\
\hline NAF & & & & 0.236 & 0.202 & 0.127 & & & & 0.160 & 0.259 & $0.652 *$ \\
\hline NPC & & & & $0.569^{*}$ & 0.687 * & $0.646^{*}$ & & & & 0.370 & $0.716^{*}$ & $0.622 *$ \\
\hline
\end{tabular}

Note: ** correlation is significant at the 0.01 level, ${ }^{*}$ correlation is significant at the 0.05 level (2-tailed). Bn: B. napus, Ov: O. violaceus.

\subsection{The Nutrient Plunder Capacity of Four Plants}

As shown in Table 5, NTR, UAF and NPC of B. papyrifera in the agricultural soil are significantly $(p<0.01)$ higher than those of $B$. papyrifera in the moderately rocky desertification soil. Moreover, crude protein, crude ash and water content of B. papyrifera in the agricultural soil are significantly $(p<0.01)$ higher than those of that in the moderately rocky desertification soil, which is in good agreement with NTR, UAF and NPC. Meanwhile, S. tuberosum has higher $(p<0.05)$ UAF compared with $C$. annuum, and its NTR, NPC, crude protein, crude ash and water content are significantly $(p<0.01)$ higher than those of C. annuum.

Table 5. The electrophysiological parameters and nutrient plunder capacity of four plants. NTR: nutrient transfer rate, NAF: the active transport flow of nutrient, NPC: the nutrient plunder capacity.

\begin{tabular}{ccccccc}
\hline Plants & NTR & UAF & NPC & $\begin{array}{c}\text { Crude Protein } \\
\text { (\%) }\end{array}$ & Crude Ash (\%) & $\begin{array}{c}\text { Water Content } \\
\text { (\%) }\end{array}$ \\
\hline AS- $B p$ & $48.80 \pm 17.12^{\mathrm{aA}}$ & $0.91 \pm 0.15^{\mathrm{aA}}$ & $43.02 \pm 11.56^{\mathrm{aA}}$ & $21.26 \pm 1.54^{\mathrm{aA}}$ & $12.55 \pm 1.03^{\mathrm{aA}}$ & $69.37 \pm 3.16^{\mathrm{aA}}$ \\
MRDS- $B p$ & $0.37 \pm 0.03^{\mathrm{bB}}$ & $0.19 \pm 0.03^{\mathrm{bB}}$ & $0.07 \pm 0.01^{\mathrm{bB}}$ & $19.10 \pm 0.72^{\mathrm{bB}}$ & $10.15^{\mathrm{b}} \pm 1.06^{\mathrm{bB}}$ & $66.37 \pm 2.01^{\mathrm{bB}}$ \\
\hline$S t$ & $66.64 \pm 17.31^{\mathrm{aA}}$ & $0.61 \pm 0.12^{\mathrm{aA}}$ & $39.18 \pm 3.58^{\mathrm{aA}}$ & $3.59 \pm 0.37^{\mathrm{aA}}$ & $4.06 \pm 0.15^{\mathrm{aA}}$ & $92.37 \pm 1.31^{\mathrm{aA}}$ \\
$C a$ & $4.16 \pm 1.34^{\mathrm{bB}}$ & $0.34 \pm 0.07^{\mathrm{bA}}$ & $1.44 \pm 0.52^{\mathrm{bB}}$ & $1.87 \pm 0.24^{\mathrm{bB}}$ & $3.65 \pm 0.21^{\mathrm{bB}}$ & $82.93 \pm 0.59^{\mathrm{bB}}$ \\
\hline
\end{tabular}

Note: Except for UAF and NPC, other data in the table are all quoted from our previous study [22,23]. Small letters indicate significant differences at $5 \%$ level $(p<0.05)$, and capital letters indicate significant differences at $1 \%$ level $(p<0.01)$. AS-Bp: B. papyrifera grown in the agricultural soil, MRDS-Bp: B. papyrifera grown in the moderate rocky desertification soil, St: S. tuberosum L., Ca: C. annuum L.

\section{Discussion}

The Nernst equation is used to quantitatively describe the diffusion potential of an ion between A and B systems; in theory, it can also be used to quantitatively describe the diffusion potential of the ions, ion groups and electric dipoles inside and outside the cell. Based on this, in our previous studies, the $\mathrm{R}, \mathrm{Z}, \mathrm{Xc}$ or $\mathrm{XL}=\mathrm{y}+\mathrm{k} e^{-\mathrm{bF}}$ of the theoretically mechanistic models between clamping force and leaf $\mathrm{R}, \mathrm{Z}, \mathrm{Xc}$ or $\mathrm{XL}$ was innovatively discovered [22,23]. The intrinsic electrophysiological parameters of plant leaves can be obtained when clamping force is 0 by fitting the equations of the clamping force and electrophysiological parameters of plant leaves. The results in this study show that the correlation coefficients $(R)$ of the fitting equations of $\mathrm{R}-\mathrm{F}, \mathrm{Xc}-\mathrm{F}$, and $\mathrm{XL}-\mathrm{F}$ in all B. napus and O. violaceus leaves were more than 0.9769 , and all $p$ values of the fitting equation parameters were lower than 0.0001 . These results also highlight that the aforementioned theoretical model has authenticity, credibility and applicability. The intrinsic electrophysiological parameters of plant leaves obtained by this approach overcome the poor representativeness, stability and reproducibility of the traditional impalement method, and it has rapid, undamaged, simple, accurate and real-time advantages.

Generally, a plant's metabolic activities are vigorous in a healthy state, and the numbers of ions, ion groups and electric dipoles (charge) stored in cells are greater, which can 
be understood as a generalized charging phenomenon. Therefore, the stronger the growth potential of plants, the more it is charged, the larger $C$ value and the lower the $R, Z, X_{C}$ and $\mathrm{XL}$ values. The previous results show that $B$. papyrifera in the agricultural soil had lower IR, IXc, IXL and IZ and higher IC, crude ash, crude protein and water content as compared to that in the moderately rocky desertification soil; $S$. tuberosum had higher IC and lower IR, IXc, IXL and IZ as compared to C. annuum [22,23]. Similar to the aforementioned, O. violaceus had higher IC and lower IR, IXc, IXL and IZ as compared to B. napus, which is consistent with the fact that the dwarf herb O. violaceus has a more vigorous life than the tall herb $B$. napus. These results also show that $O$. violaceus has superior ion affinity and a higher concentration difference between the inside and outside cells as compared to B. napus. Correlation analysis shows that IR, IXc, IXL and IZ are negatively correlated with water content, crude protein and crude ash, while IC is positively correlated with those. IR of $B$. napus is significantly correlated with its crude protein, IXc, IXL and IZ of O. violaceus are significantly correlated with its crude protein. IXL of B. napus is significantly correlated with its crude ash. IXc of B. napus is significantly correlated with water content, and its IZ and IC are significantly correlated with water content; IR, IXc, IXL and IZ of O. violaceus are significantly correlated with water content, and its IC is significantly correlated with its water content. These results also perfectly prove the accuracy of the above results, which support that the evaluation of a plant's electrophysiological parameters in various physiological states is reliable.

The nutrient metabolism, growth and development of plants are strongly affected by nutrient transport or plunder, and plants have different adaptive mechanisms to lownutrient environments. Although the minimum concentration of plant ion absorption can reflect a plant's nutrient plunder capacity, its operation is complex, time consuming and demanding, and cannot be used for in situ online determination [6]. Cell membrane proteins are most closely related to the nutrient transport inside and outside the plant cells, and its binding proteins play the most dominant role in nutrient transport $[33,34]$. The active transport capacity of nutrients dominated by binding proteins can be equivalent to the plunder capacity of plants to nutrients. In our previous study, NTC based on leaf $R, Z$, $X_{c}, X L$ and $C$ perfectly revealed the nutrient transport strategies of various plants [23]. NTC represented the overall transport capacity of cell membrane proteins to plant nutrients, but it could not directly represent the active transport capacity (or plunder capacity) of plant nutrients. The results in previous study demonstrate that $X_{c}$ and XL could, respectively, represent the relative composition characteristic of surface and binding proteins in the cell membrane. Thus, the ratio of $\mathrm{Xc}_{\mathrm{c}}$ and $\mathrm{XL}$ can represent the relative plunder information (or active transport information) of plant nutrients.

Due to the low nutrition, drought, high $\mathrm{pH}$, high bicarbonate and high calcium and magnesium of karst soil environments, low nutrition is one of the most frequent and harmful environmental stresses faced by plants $[4-6,20,28]$. Wu et al. [6] put forward that the adaptive mechanisms of the karst-adaptable plants include a photosynthesis mechanism, inorganic nutrition mechanism, carbonic anhydrase mechanism, biological diversity mechanism, calcium regulation and high calcium adaptation mechanism and root organic acid exudation mechanism. On the basis of these adaptive mechanisms, they found that $O$. violaceus was better adapted to karst environments compared with $B$. napus. In this study, NAF and NPC of plants based on leaf IZ, IXc, IXL and IC were defined to evaluate the nutrient plunder capacity of plants. The results indicate that NTR, NTC, NPC, water content, crude protein and crude ash of $O$. violaceus are significantly higher $(p<0.01)$ than those of $B$. napus, while its UNF and UAF are significantly $(p<0.05)$ lower than those of $B$. napus. These results demonstrate that the high protein, ash and water content of O. violaceus supported its high NTR, which enhanced its NTC and NPC, while B. napus could adapt to survival by improving its UNF and UAF. Consistent with the above report, this study further proves that $O$. violaceus had superior ion affinity and higher adaptability to karst environments as compared to B. napus. 
In our previous studies, the results show that Broussonetia papyrifera in the agricultural soil had lower UNF and higher NTR, NTC, crude ash, crude protein and water content as compared to that in the moderately rocky desertification soil; Solanum tuberosum L. with high ash and protein content had higher NTR, NTC and lower UNF than Capsicum annuum L. with low ash and protein content [22,23]. The results here indicate that the high protein, ash and water content of B. papyrifera in the agricultural soil supported its high NTR, UAF and ion affinity, which enhanced the transport, plunder and utilization of nutrients. S. tuberosum has higher $(p<0.05)$ UAF compared with $C$. annuum, and its NTR, NPC, crude protein, crude ash and water content are significantly $(p<0.01)$ higher than those of $C$. annuum. These results further highlight that UAF and NPC based on a plant's electrophysiological information have good reliability and universal applicability for evaluating the nutrient plunder capacity of plants.

The results show that IR, IXc, IXL and IZ are negatively correlated with NTR, UAF and NPC, while IC is positively correlated with those. NTR of B. napus is significantly correlated with its crude protein, and NTR of $O$. violaceus is significantly correlated with its crude protein and water content. NAF of $O$. violaceus is significantly correlated with its water content. NPC of B. napus is significantly correlated with its crude protein, crude ash and water content, and NPC of $O$. violaceus is significantly correlated with its crude ash and water content. These results demonstrate that NTR, UAF and NPC of plants had good correlations with nutrients and water, which supports that NTR, UAF and NPC used to evaluate nutrient plunder of plants is reliable and feasible. Moreover, the correlation coefficients between some parameters were strongly different in B. napus and O. violaceus, for example IR and water content, which might be caused by the different water status of the plants at the time of determination. O. violaceus with high water content had some higher correlation coefficients than B. napus with low water content. When plants are in low water status, the mechanisms of plants' adaptation to water are not mainly regulated by vacuole concentration, but by vacuole concentration and cell volume, etc., and this regulation is nonlinear [20].

Meanwhile, four nutrient plunder modes in the tested plants were found, which are (1) low NTR, high UAF, low NPC (Bn), (2) high NTR, low UAF, high NPC (Ov), (3) high NTR, high UAF, high NPC (AS-Bp, St) and (4) low NTR, low UAF, low NPC $(C a)$. The results exhibit that the nutrient plunder of plants has diversity, and other nutrient plunder models of plants should be found in the future. To our knowledge, the rapid determination of a plant's nutrient plunder capacity has not been reported. In this study, NAF and NPC were defined based on leaf IZ, IXc, IXL and IC for the first time, which accurately revealed the plunder capacity and adaptive strategies of plants to nutrients. Moreover, NAF and NPC have commendable representativeness, stability and reproducibility due to the fact that they are obtained by the intrinsic electrical parameters of plants. This study highlights that NAF and NPC based on a plant's electrical information have good reliability, feasibility and universality for evaluating the nutrient plunder capacity of plants, and that O. violaceus has superior ion affinity and higher adaptability to low-nutrient environments as compared to B. napus.

\section{Conclusions}

The present study reveals the nutrient plunder modes of B. napus and O. violaceus, and provides a novel, rapid, reliable method based on a plant's electrophysiological information for real-time determination of the nutrient plunder capacity of plants. NAF and NPC were firstly exploited in the light of leaf IZ, IXc, IXL and IC, which precisely represented and revealed the plunder capacity and adaptive strategies of plants to nutrients. $O$. violaceus had higher $(p<0.01)$ NPC and IC and lower $(p<0.01)$ IR, IXc, IXL and IZ as compared to $B$. napus, which supported that it had a superior ion affinity and could be better adapted to low-nutrient environments. 
Author Contributions: Y.W. constructed and conceived the project. Y.W., Y.S., and C.Z. designed the research. C.Z., Y.Z. and H.L. performed the research. C.Z. and D.X. analyzed the data. C.Z., Y.S. and Y.W. wrote the paper. All authors read and approved the final manuscript.

Funding: This research was funded by the National Key Research and Development Program of China [2021YFD1100300], the Support Plan Projects of the Science and Technology Department of Guizhou Province (No. (2021)YB453), the Science and Technology Innovation Talent Project of Guizhou Province (No. (2016)5672).

Institutional Review Board Statement: Not applicable.

Informed Consent Statement: Not applicable.

Data Availability Statement: The datasets during or analyzed during the current study available from the corresponding author on reasonable request.

Conflicts of Interest: The authors declare no conflict of interest.

\begin{abstract}
Abbreviations
$\mathrm{C}$ : capacitance, Z: impedance, R: resistance, $\mathrm{Xc}_{\mathrm{c}}$ capacitive reactance, $\mathrm{XL}$ : inductive reactance, F: clamping force, IR: intrinsic resistance, IXc: intrinsic capacitive reactance, IXL: intrinsic inductive reactance, IZ: intrinsic impedance, IC: intrinsic capacitance, UNF: the nutrient flux per unit area, NTR: nutrient transfer rate, NTC: nutrient transport capacity, NAF: the active transport flow of nutrient, NPC: the nutrient plunder capacity.
\end{abstract}

\title{
References
}

1. Hopkins, W.G.; Huner, N.P.A. Introduction to Plant Physiology, 3rd ed.; John Wiley \& Sons Inc.: New York, NY, USA, $2004 ;$ p. 89.

2. Aziz, T.; Ahmed, I.; Farooq, M.; Maqsood, M.A.; Sabir, M. Variation in phosphorus efficiency among Brassica cultivars I: Internal utilization and phosphorus remobilization. J. Plant Nutr. 2011, 34, 2006-2017. [CrossRef]

3. Paungfoo-Lonhienne, C.; Visser, J.; Lonhienne, T.G.A.; Schmidt, S. Marschner review. Past, present and future of organic nutrients. Plant Soil 2012, 359, 1-18. [CrossRef]

4. Lu, X.; Toda, H.; Ding, F.; Fang, S.; Xu, H. Effect of vegetation types on chemical and biological properties of soils of karst ecosystems. Eur. J. Soil Biol. 2014, 61, 49-57. [CrossRef]

5. Li, D.; Liu, J.; Chen, H.; Zheng, L.; Wang, K. Soil microbial community responses to forage grass cultivation in degraded karst soils, Southwest China. Land Degrad. Dev. 2018, 29, 4262-4270. [CrossRef]

6. Wu, Y.Y.; Xing, D.K.; Hang, H.T.; Zhao, K. Principles and Technology of Determination on Plant' Adaptation to Karst Environment; Science Press: Beijing, China, 2019; pp. 27-28.

7. Xing, D.K.; Wu, Y.Y. Effects of low nutrition on photosynthetic capacity and accumulation of total $\mathrm{N}$ and $\mathrm{P}$ in three climber plant species. Chin. J. Geochem. 2015, 34, 115-122. [CrossRef]

8. Fromm, J.; Lautner, S. Electrical signals and their physiological significance in plants. Plant Cell Environ. $2010,30,249-257$. [CrossRef] [PubMed]

9. Volkov, A.G. Plant Electrophysiology: Theory and Methods; Springer: Berlin, Germany, 2006.

10. Szechyńska-Hebda, M.; Lewandowska, M.; Karpiński, S. Electrical signaling, photosynthesis and systemic acquired acclimation. Front. Physiol. 2017, 8, 684. [CrossRef] [PubMed]

11. Sukhov, V. Electrical signals as mechanism of photosynthesis regulation in plants. Photosynth. Res. 2016, 130, 373-387. [CrossRef] [PubMed]

12. Buckley, D.J.; Lefebvre, M.; Meijer, E.G.M.; Brown, D.C.W. A signal generator for electrofusion of plant protoplasts. Comput. Electron. Agric. 1990, 5, 179-185. [CrossRef]

13. Sukhov, V.; Surova, L.; Sherstneva, O.; Bushueva, A.; Vodeneev, V. Variation potential induces decreased PSI damage and increased PSII damage under high external temperatures in pea. Funct. Plant Biol. 2015, 42, 727-736. [CrossRef]

14. Sukhov, V.; Gaspirovich, V.; Mysyagin, S.; Vodeneev, V. High-temperature tolerance of photosynthesis can be linked to local electrical responses in leaves of Pea. Front. Physiol. 2017, 8, 763. [CrossRef]

15. Favre, P.; Greppin, H.; Agosti, R.D. Accession-dependent action potentials in Arabidopsis. J. Plant Physiol. 2011, 168, 653-660. [CrossRef]

16. Gil, P.M.; Gurovich, L.; Schaffer, B.; Alcayaga, J.; Rey, S.; Iturriaga, R. Root to leaf electrical signaling in avocado in response to light and soil water content. J. Plant Physiol. 2008, 165, 1070-1078. [CrossRef]

17. Gallé, A.; Lautner, S.; Flexas, J.; Fromm, J. Environmental stimuli and physiological responses: The current view on electrical signaling. Environ. Exp. Bot. 2015, 114, 15-21. [CrossRef] 
18. Macedo, F.C.O.; Dziubinska, H.; Trebacz, K.; Oliveira, R.F.; Moral, R.A. Action potentials in abscisic acid-deficient tomato mutant generated spontaneously and evoked by electrical stimulation. Acta Physiol. Plant. 2015, 37, 1-9. [CrossRef]

19. Wang, Z.Y.; Qin, X.H.; Li, J.H.; Fan, L.F.; Zhou, Q.; Wang, Y.Q.; Zhao, X.; Xie, C.J.; Wang, Z.Y.; Huang, L. Highly reproducible periodic electrical potential changes associated with salt tolerance in wheat plants. Environ. Exp. Bot. 2019, 160, 120-130. [CrossRef]

20. Zhang, M.M.; Wu, Y.Y.; Xing, D.K.; Zhao, K.; Yu, R. Rapid measurement of drought resistance in plants based on electrophysiological properties. Trans. ASABE 2015, 58, 1441-1446.

21. Xing, D.K.; Chen, X.; Wu, Y.Y.; Zwiazek, J.J. Leaf physiological impedance and elasticity modulus in Orychophragmus violaceus seedlings subjected to repeated osmotic stress. Sci. Hortic. 2021, 276, 109763. [CrossRef]

22. Zhang, C.; Wu, Y.Y.; Su, Y.; Xing, D.K.; Dai, Y.; Wu, Y.S.; Fang, L. A plant's electrical parameters indicate its physiological state: A study of intracellular water metabolism. Plants 2020, 9, 1256. [CrossRef] [PubMed]

23. Zhang, C.; Wu, Y.Y.; Su, Y.; Li, H.T.; Fang, L.; Xing, D.K. Plant's electrophysiological information manifests the composition and nutrient transport characteristics of membrane proteins. Plant Signal. Behav. 2021, e1918867. [CrossRef] [PubMed]

24. Chen, Y.; Zhao, D.J.; Wang, Z.Y.; Wang, Z.Y.; Tang, G.; Huang, L. Plant electrical signal classification based on waveform similarity. Algorithms 2016, 9, 70. [CrossRef]

25. Zhao, D.J.; Wang, Z.Y.; Li, J.; Wen, X.; Liu, A.; Wang, X.D.; Hou, R.F.; Wang, C.; Huang, L. Recording extracellular signals in plants: A modeling and experimental study. Math. Comput. Model. 2013, 58, 556-563. [CrossRef]

26. Harker, F.R.; Dunlop, J. Electrical impedance studies of nectarines during coolstorage and fruit ripening. Postharvest Biol. Technol. 1994, 4, 125-134. [CrossRef]

27. Ibba, P.; Falco, A.; Abera, B.D.; Cantarella, G.; Petti, L.; Lugli, P. Bio-impedance and circuit parameters: An analysis for tracking fruit ripening. Postharvest Biol. Technol. 2020, 159, 110978. [CrossRef]

28. Javed, Q.; Wu, Y.Y.; Xing, D.K.; Azeem, A.; Ullah, I.; Zaman, M. Re-watering: An effective measure to recover growth and photosynthetic characteristics in salt-stressed Brassica napus L. Chil. J. Agric. Res. 2017, 77, 78-86. [CrossRef]

29. Xing, D.K.; Xu, X.J.; Wu, Y.Y.; Liu, Y.J.; Wu, Y.S.; Ni, J.H.; Azeem, A. Leaf tensity: A method for rapid determination of water requirement in formation in Brassica napus L. J. Plant Interact. 2018, 13, 380-387. [CrossRef]

30. Kertész, Á.; Hlaváčová, Z.; Vozáry, E.; Staroňová, L. Relationship between moisture content and electrical impedance of carrot slices during drying. Int. Agrophys. 2015, 29, 61-66. [CrossRef]

31. Borges, B.M.M.N.; Strauss, M.; Camelo, P.A.; Sohi, S.P.; Franco, H.C.J. Re-use of sugarcane residue as a novel biochar fertilizerIncreased phosphorus use efficiency and plant yield. J. Clean. Prod. 2020, 262, 121406. [CrossRef]

32. Geng, Y.J.; Chen, L.; Yang, C.; Jiao, D.Y.; Zhang, Y.H.; Cai, Z.Q. Dry-season deficit irrigation increases agricultural water use efficiency at the expense of yield and agronomic nutrient use efficiency of Sacha Inchi plants in a tropical humid monsoon area. Ind. Crop. Prod. 2017, 109, 570-578. [CrossRef]

33. Sondergaard, T.E.; Palmgren, S. Energization of transport processes in plants. roles of the plasma membrane $\mathrm{H}^{+}$-ATPase. Plant Physiol. 2004, 136, 2475-2482. [CrossRef]

34. Nguyen, C.T.; Kurenda, A.; Stolz, S.; Chetelat, A.; Farmer, E.E. Identification of cell populations necessary for leaf-to-leaf electrical signaling in a wounded plant. Proc. Natl. Acad. Sci. USA 2018, 115, 10178-10183. [CrossRef] [PubMed] 